\title{
The Azambuja fault: An active structure located in an intraplate basin with significant seismicity (Lower Tagus Valley, Portugal)
}

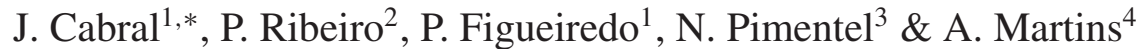 \\ ${ }^{1}$ Fac. Ciências de Lisboa, Dep. Geologia and LATTEX, Ed. C6, $2^{\circ}$ Piso, Campo Grande, 1749-016 Lisboa, \\ Portugal; ${ }^{2}$ Obs. Magnético do Inst. Geof., Univ. de Coimbra, R. Anibal Lima, 3800 Coimbra, Portugal; ${ }^{3}$ Fac. \\ Ciências de Lisboa, Dep. Geologia and GeoCgul, Ed. C6, $2^{\circ}$ Piso, Campo Grande, 1749-016 Lisboa, Portugal; \\ ${ }^{4}$ Dep. Geociências, Univ Évora, 7002-554 Évora, Portugal, *Author for correspondence: e-mail: jcabral@fc.ul.pt
}

Received 3 March 2003; accepted in revised form 24 November 2003

Key words: active faulting, neotectonics, seismotectonics, Lower Tagus Valley, Portugal

\begin{abstract}
The Azambuja fault is a NNE trending structure located $50 \mathrm{~km} \mathrm{NE}$ of Lisbon, in an area of important historical seismicity. It is sited in the Lower Tagus Basin, a compressive foredeep basin related to tectonic inversion of the Mesozoic Lusitanian Basin in the Miocene. The fault is evident in commercial seismic reflection data, where it shows steep thrust geometry downthrowing the Cenozoic sediments to the east. It has also a clear morphological signature, presenting a NNE-SSW trending, east facing, $15 \mathrm{~km}$ long scarp, reaching a maximum height of $80 \mathrm{~m}$. The fault scarp is the geomorphic appearance of a flexure expressed as a zone of distributed deformation, where Miocene and Pliocene sediments are tilted eastwards and are cut by steeply dipping meso-scale faults presenting reverse and normal offsets, with a net downthrow to the east. This pattern at the surface is compatible with a steep fault in the basement that tilts and branches through the overlying Cenozoic sedimentary cover. In order to constrain the neotectonic activity of this structure, detailed geological studies were conducted. Morphotectonics was studied through aerial photo interpretation, analysis of topographic maps and digital mapping. Those studies indicate Quaternary slip on the fault in the ranges of $0.05-0.06 \mathrm{~mm}$ per year. Seismogenic behaviour was assumed for the Azambuja fault based on the evidence of Quaternary tectonic activity and its location in an area of significant historical seismicity. $M_{\mathrm{w}}$ 6.4-6.7 maximum earthquakes, with recurrence intervals of 10000-25000 years, were estimated based upon the displaced morphological references, cumulative offsets and fault length.
\end{abstract}

\section{Introduction}

The Azambuja fault is a NNE-SSW trending structure located in the Lower Tagus River Valley (LTV), 50 $\mathrm{km}$ NE of Lisbon, within the Lower Tagus Cenozoic Sedimentary Basin (LTB) (Figure 1). The LTV area is the site of important seismicity, attested by the occurrence of moderate to large historical earthquakes, as in 1344(?) 1531 and 1909 (Mezcua, 1982; Moreira, 1985, 1991; Oliveira, 1986; Oliveira and Sousa, 1991) (Figure 2). This earthquake activity represents a serious seismic hazard for this densely populated region. The occurrence of earthquakes indicates the presence of seismogenic faults in the study region that are still poorly constrained due to the low slip-rates and the presence of a thick Holocene sedimentary cover that conceals several of the faults in the underlying basement (Cabral and Ribeiro, 1988; Cabral, 1995).

It is frequently considered that the large seismic events that occurred in the area (as in 1531 and 1909) were generated by the Lower Tagus Valley Fault, an alleged major NNE-SSW regional structure whose presence was assumed since the beginning of the 20th century (Bensaúde, 1910; Freire de Andrade, 1933). However, so far this fault has never been confidently recognized, whereas there is evidence for the presence of other active structures, as the Azambuja fault, that must be considered in the regional 